\title{
Absolute Configuration Assignment of Ortho, Meta, or Para Isomers by Mass Spectrometry
}

\author{
Luis Alberto B. Moraes, Adão A. Sabino, Eduardo C. Meurer, \\ and Marcos N. Eberlin \\ Institute of Chemistry, State University of Campinas, Campinas, Brazil
}

\begin{abstract}
A general method based solely on mass spectrometric techniques for the absolute configuration assignment of ortho, meta, or para isomers of acyl nitrobenzenes and derivatives is described. Instead of comparing the mass spectra of the three intact molecules of each positional isomer and investigating each one of the many sets of positional isomers, the method generalizes the effort by performing structural analysis on configurationally diagnostic fragment ions that are common for a given class of compounds. These ions must therefore retain the positional information of the parent molecules and be unequivocally distinguished. Nitrobenzoyl cations are common and stable fragment ions of most acyl nitrobenzenes and derivatives retaining the respective ortho, meta, or para configuration of the precursor molecules. The different $\mathrm{NO}_{2}$ and $\mathrm{CO}^{+}$ring alignments profoundly influence their collisioninduced dissociation and bimolecular reactivity, and the isomeric 2-, 3-, and 4nitrobenzoyl cations are found to be unequivocally distinguished using both approaches. Absolute ortho, meta, or para positional assignment by tandem MS of every isomeric molecule of the acyl nitrobenzene class and derivatives forming detectable amounts of any of those diagnostic nitrobenzoyl cations is, therefore, possible. The ability to perform absolute (non-comparative) configuration assignment using such diagnostic ions is exemplified for a single test molecule of $(2 \mathrm{R})-(-)-2$-methylglycidyl 4-nitrobenzoate. The general application of this absolute MS-only method for other classes of positional isomers is discussed. (J Am Soc Mass Spectrom 2005, 16, 431-436) (C) 2004 American Society for Mass Spectrometry
\end{abstract}

A bsolute configuration assignment of isomers such as cis/trans pairs or ortho/meta/para sets based solely on mass spectrometry (MS) data is a very challenging, most often unfeasible task. Configuration assignments are therefore performed indirectly, by comparison of MS data, in an effort that requires access to all isomers within the set and previous configuration assignments by other techniques. Mass spectra are then acquired hoping that each ionized molecule will dissociate to form a unique, structurally diagnostic fragment ion. Otherwise, each neutral or ionized molecule may be found to display characteristic ion-molecule reactivity and to form a unique, structurally diagnostic product ion. When unique ions are not observed, significant variations in product ion ratios from dissociation or bimolecular reactions can still be used for comparative isomer distinction.

Sets of isomers tend to display, however, undistinguishable dissociation and bimolecular chemistries, hence these comparative MS methods eventually fail. For a single and novel molecule of unknown configuration, it is

Published online February 5, 2005

Address reprint requests to Dr. M. N. Eberlin, Thomson Mass Spectrometry Laboratory, Institute of Chemistry, State University of Campinas-UNICAMP CP 6154, 13083-970 Campinas SP, Brazil. E-mail: eberlin@iqm.unicamp.br unlikely that an absolute MS configuration assignment can be successful using the approaches just described.

We thought, therefore, to base MS configuration assignment on structural analysis not of the target molecules but of configurationally diagnostic fragment ions in which the positional information is preserved. Pyridyl and pyrimidyl cations are examples of such diagnostic ions since positional information of ring substituents in either the ionized or protonated precursor molecule is preserved upon $\mathrm{R}$ or $\mathrm{RH}$ loss (the positive charge is placed on a localized $\mathrm{sp}^{2}$ orbital), and "H-ring walking" is prevented by high energy barriers (Scheme 1)[1]. We have recently demonstrated [2] that 2-, 4-, and 5-pyrimidyl cations (Scheme 1) function as such conformationally diagnostic ions for sets of isomeric mono-substituted pyrimidines, and that 2-substituted pyridines can be distinguished from the 3- and 4-isomers using diagnostic pyridyl cations.

Mono-substituted benzoyl cations are also attractive candidates for conformationally diagnostic ions since they are common and stable [3] fragment ions retaining the position information of acyl substituents in their formal charge site, that is, the $\mathrm{CO}^{+}$group (Scheme 2). Hence, distinction of mono-substituted benzoyl cations would allow absolute and general configuration assign- 


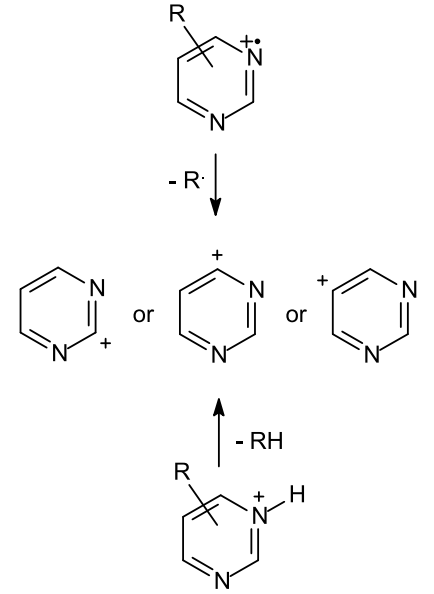

Scheme 1

ment of ortho, meta, and para isomers of most disubstituted acylbenzenes and derivatives. These derivatives would include acyl, carbohydroxy, carboxyalkyl, carboxyhalogen, and amidyl substituted nitrobenzenes of many types and structures, comprising many synthetic, industrial, and pharmaceutical relevance. These related classes constitute an interesting proof-of-principle case for the present method since many of their sets of ortho, meta, and para isomers display nearly identical, undistinguishable $70 \mathrm{eV}$ EI mass spectra, so the comparative MS methods discussed above for configuration assignment applied specifically to each set of isomers are likely to fail in many cases.

Herein we report a study in which the 2-, 3-, and 4-nitrobenzoyl cations 1a-c were tested as configurationally diagnostic ions for general and absolute configuration assignment of acyl nitrobenzene molecules or derivatives. The method has been tested using the single isomeric molecule of (2R)-(-)-2-methylglycidyl 4-nitrobenzoate (2).

\section{Experimental}

$\mathrm{MS}^{2}$ and $\mathrm{MS}^{3}$ experiments were performed with an Extrel pentaquadrupole mass spectrometer [4]. The $\mathrm{Q}_{1} \mathrm{q}_{2} \mathrm{Q}_{3} \mathrm{q}_{4} \mathrm{Q}_{5}$ consists of three mass-analyzing quadrupoles $\left(Q_{1}, Q_{3}, Q_{5}\right)$ in which ion-mass selection and analysis are performed, and two reaction quadrupoles $\left(\mathrm{q}_{2}, \mathrm{q}_{4}\right)$ which are used to perform either structurally selective low-energy (near zero $\mathrm{eV}$ ) ion-molecule reactions [5] or $15 \mathrm{eV}$ collision induced dissociation (CID) [6] with argon. For the two-stage $\mathrm{MS}^{2}$ experiments, the ions of interest were generated by dissociative $70 \mathrm{eV}$ EI of the following isomeric precursors: 1a (2-nitroaceto-

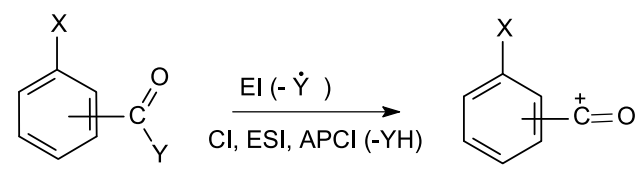

Scheme 2<smiles>O=Cc1ccccc1[N+](=O)[O-]</smiles><smiles>O=[C+]c1cccc([N+](=O)[O-])c1</smiles><smiles>O=C[C+]c1ccc([N+](=O)[O-])cc1</smiles>

Structure 1

phenone), 1b (3-nitroacetophenone), and 1c (4-nitroacetophenone). After ion-molecule reactions or CID in $\mathrm{q}_{2}$, $\mathrm{Q}_{5}$ was scanned to record the product ion spectra, while operating $\mathrm{Q}_{3}$ in the non-mass analyzing rf-only mode. For the $\mathrm{MS}^{3}$ experiments, a q2-product ion of interest was mass-selected by Q3 for further $15 \mathrm{eV}$ collisioninduced dissociation (CID) with argon in q4, while scanning Q5 to record the mass spectrum. The collision energies, calculated as the voltage difference between the ion source and the collision quadrupole, were typically near $1 \mathrm{eV}$ for ion-molecule reactions and $15 \mathrm{eV}$ for CID both in $\mathrm{MS}^{2}$ and $\mathrm{MS}^{3}$ experiments.

\section{Results and Discussion}

Figure 1 displays the $70 \mathrm{eV}$ EI mass spectra of the ortho/meta/para set of isomeric nitroacetophenones. Note that all three spectra display either unique ions or characteristic ratios of product ions, or both, which allow their distinction and therefore comparative configuration assignment. It is unlikely, however, that one could directly relate (with no previous knowledge of configuration) the dissociation patterns of these ionized molecules to their particular configurations. Each of the three isomers, however, forms the respective nitrobenzoyl cation of $\mathrm{m} / \mathrm{z} 150$ to a great extent. If these ions can be distinguished, they would function as suitable diagnostic ions for absolute MS-only configuration assignment of every known or novel precursor molecule within the class.

\section{$15 \mathrm{eV}$ CID Behavior}

The dissociation chemistry of gaseous isomeric nitrobenzoyl cations has been extensively studied for mass spectra interpretation [7], but no systematic evaluation of their low energy CID chemistry is reported. Fortunately, we found that each of the three isomeric nitrobenzoyl cations 1a-c, as the result of relative ortho, meta, or para positions of the $\mathrm{NO}_{2}$ and $\mathrm{CO}^{+}$groups in the

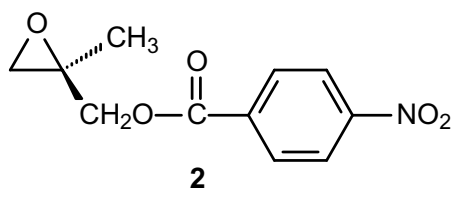

Structure 2 


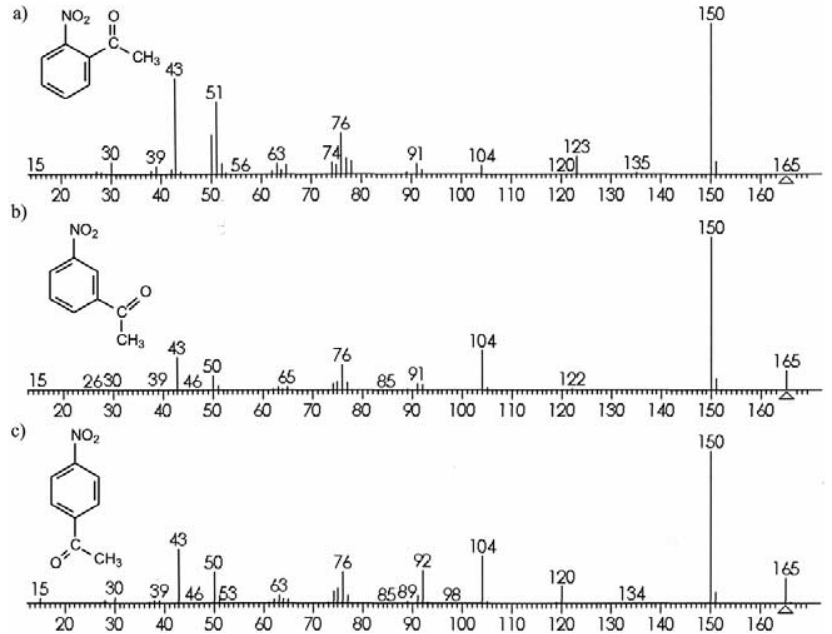

Figure 1. $70 \mathrm{eV}$ EI mass spectra of the (a) ortho, (b) meta, and (c) para-nitro acetophenones. Adapted from the NIST/EPA/NIH mass spectral library software version $1.6 \mathrm{~d}$.

benzene ring, displays very characteristic CID behavior (Figure 2). The ortho isomer 1a forms a unique fragment ion of $\mathrm{m} / \mathrm{z} 78$, the meta isomer $\mathbf{1} \mathbf{b}$ is characterized by forming a pair of major fragment ions of $\mathrm{m} / \mathrm{z} 104$ and 76, and the para isomer $1 \mathrm{c}$ forms a unique fragment ion of $\mathrm{m} / \mathrm{z} 120$ and the ion of $\mathrm{m} / \mathrm{z} 92$ as its most abundant fragment. Schemes 3, 4, and 5 rationalize the diverse and contrasting dissociation chemistries of the isomeric ions 1a-c.

\section{Bimolecular Ion Chemistry: Polar}

\section{Transacetalization with 2-Methyl-1,3-Dioxolane}

Nitrobenzoyl cations belong to the more general class of acylium ions, and we have studied extensively the gas-phase ion-molecule chemistry of such common and
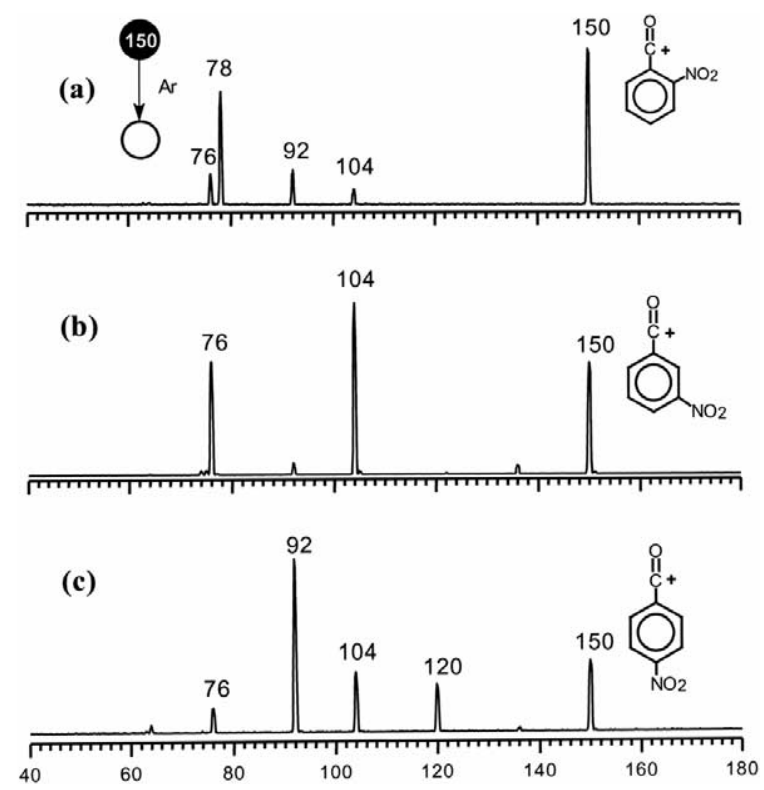

Figure 2. Product ion mass spectra for $15 \mathrm{eV} \mathrm{CID} \mathrm{with} \mathrm{argon} \mathrm{of}$ the isomeric nitrobenzoyl cations $\mathbf{1 a}-\mathbf{c}$ of $m / z 150$.

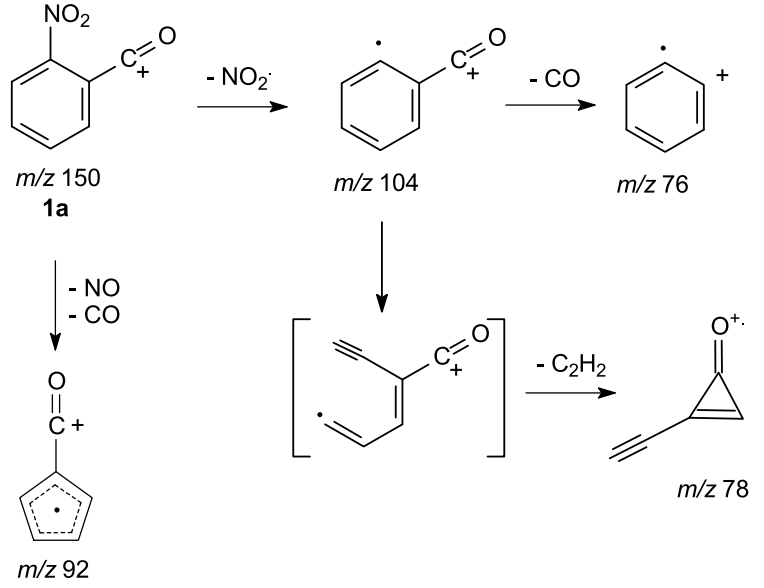

Scheme 3

important ions [8]. Among the novel reactions revealed by these studies, polar transacetalization with cyclic acetals that form cyclic ionic acetals [9] has been shown to be favored for gaseous acylium ions, and this quite general reaction has found a number of structural and analytical applications [10]. Recently, we have performed such reactions with considerably more polar and heavier cyclic acetals under unique in-source APCI and ESI ion-molecule reaction conditions [11]. Polar transacetalization with 2-methyl-1,3-dioxolane was therefore tested as an additional MS technique able to characterize the isomeric nitrobenzoyl cations 1a-c.

The ortho isomer 1a of $\mathrm{m} / \mathrm{z} 150$ is found to react promptly with 2-methyl-1,3-dioxolane ( $88 \mathrm{Da}$ ) via polar transacetalization, and to form nearly exclusively the expected cyclic ionic acetal of $m / z 194$ (Figure 3a) after the loss of acetaldehyde (Scheme 6). The ion 1a is also found to react promptly towards acetalization [12] with methoxyethanol and three-to-five membered ring expansion (the "gas phase Meerwein reaction" [13]) with epichlorohydrin, whereas $\mathbf{1 b}$ and $\mathbf{1 c}$ are less reactive in this order (spectra not shown).

The meta isomer $\mathbf{1 b}$ also reacts promptly with 2-methyl-1,3-dioxolane by polar transacetalization to form the product ion of $\mathrm{m} / \mathrm{z} 194$ (Scheme 7), but four other product ions are also clearly detected (Figure $3 \mathrm{~b}$ ). Those ions of $\mathrm{m} / \mathrm{z} 104$ and 76 are the characteristic fragments of $\mathbf{1 b}$ (compare with Figure $2 \mathrm{~b}$ ), and therefore they are likely to result from CID of $\mathbf{1 b}$ occurring even under the very low, near $1 \mathrm{eV}$ collision energy used to favor bimolecular reactions. The ion of $\mathrm{m} / \mathrm{z} 87$ is the hydride abstraction product ion ${ }^{8}$ whereas the ion of

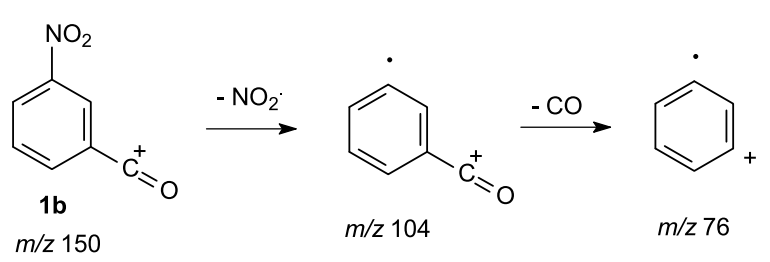

Scheme 4 


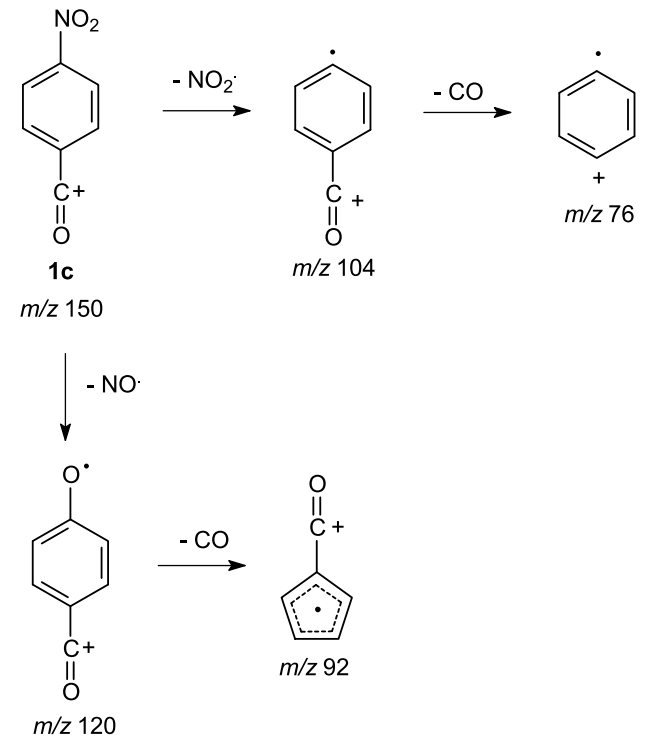

Scheme 5

$\mathrm{m} / \mathrm{z} 148$ is the distonic cyclic ionic acetal formed via polar transacetalization of the dehydrobenzoyl cation of m/z 104 with 2-methyl-1,3-dioxolane (Scheme 7) [14].

The para isomer $\mathbf{1 c}$ also reacts promptly with 2-methyl1,3-dioxolane by polar transacetalization to form the product ion of $\mathrm{m} / \mathrm{z} 194$ (Scheme 8), but it forms a much more diverse set of product ions (Figure 3c). Those of $\mathrm{m} / \mathrm{z}$ 120, 104,92 , and 76 are the characteristic fragments of $1 \mathbf{c}$ (compare with Figure 2c). The ion of $\mathrm{m} / \mathrm{z} 87$ is again the hydride abstraction product ion [8]. The ions of $\mathrm{m} / \mathrm{z} 136$ and 164 are likely the cyclic ionic acetals formed from
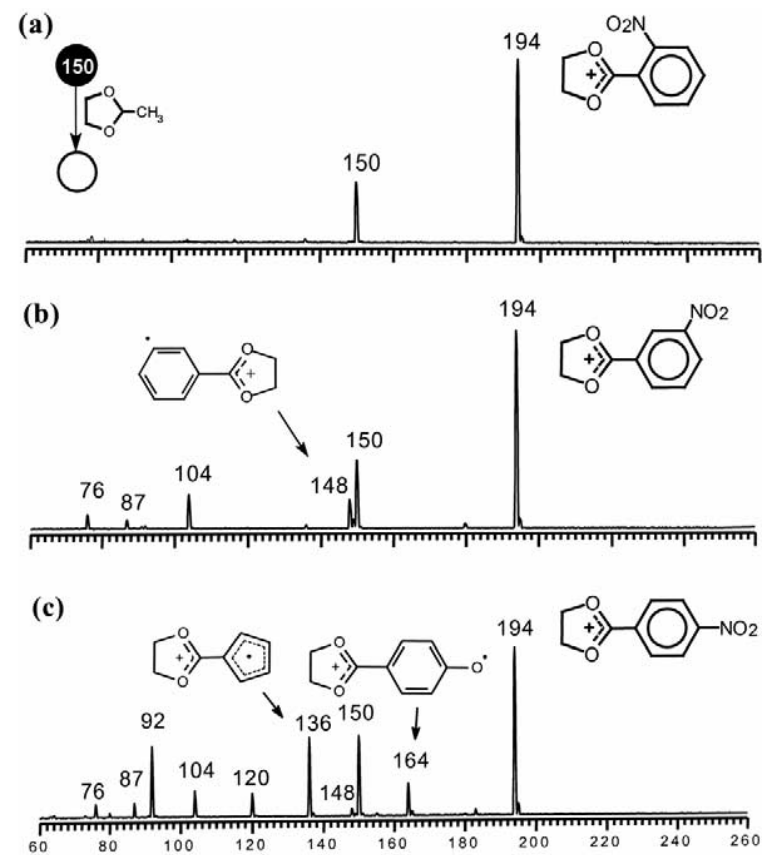

Figure 3. Product ion mass spectra for reactions of the massselected isomeric nitrobenzoyl cations (a) $\mathbf{1 a},(\mathbf{b}) \mathbf{1} \mathbf{b}$, and (c) $\mathbf{1 c}$ of $\mathrm{m} / \mathrm{z} 150$ with 2-methyl-1,3-dioxolane.

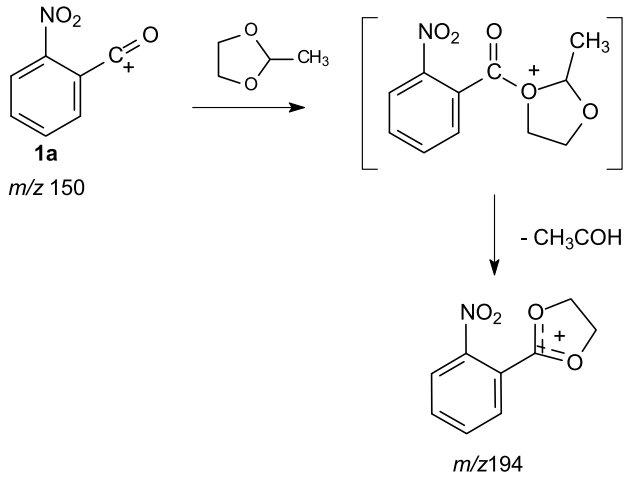

Scheme 6

polar transacetalization of the ions of $\mathrm{m} / \mathrm{z} 92$ and 120, respectively (Scheme 8). Note that these structural assignments of cyclic ionic acetals are supported by $\mathrm{MS}^{3}$ experiments, that is, when each putative cyclic ionic acetal is mass selected (by Q3) and then dissociated by $15 \mathrm{eV}$ collisions with argon (in q4), loss mainly of a neutral molecule of $44 \mathrm{Da}$ that reforms the reactant ion is observed. This dissociation is common and characteristic for cyclic ionic acetals [8].

The product ion mass spectra (Figure 3 ) for reactions with 2-methyl-1,3-dioxolane provide therefore characterization based on an interesting combination of CID plus ion-molecule reactions, which further enhances the unequivocal structural assignment of each of the three configurationally diagnostic ions, that is, the isomeric 2-, 3-, and 4-nitrobenzoyl cations.

\section{Testing a Single Molecule}

To show that the method is indeed absolute in a sense that it can handle every molecule of unknown configuration with no need for MS spectra comparison within the whole set of isomers, the single acyl nitrobenzene derivative (2R)-(-)-2-methylglycidyl 4-nitrobenzoate 2 was selected as an illustrative single molecule. This para isomer is an

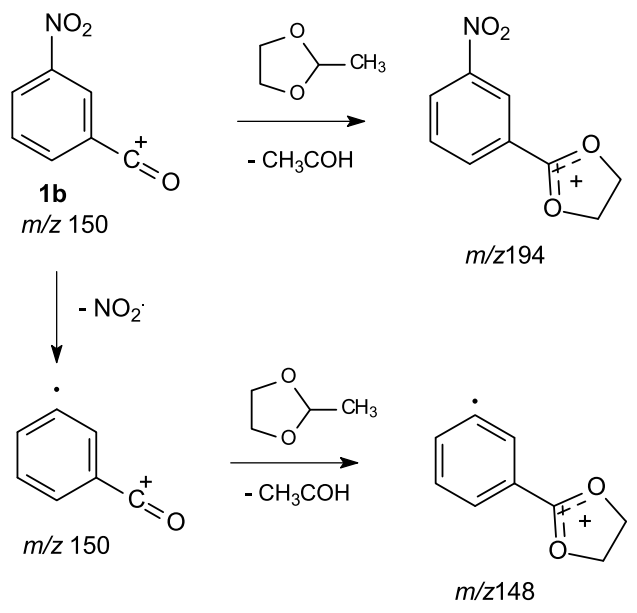

Scheme 7 


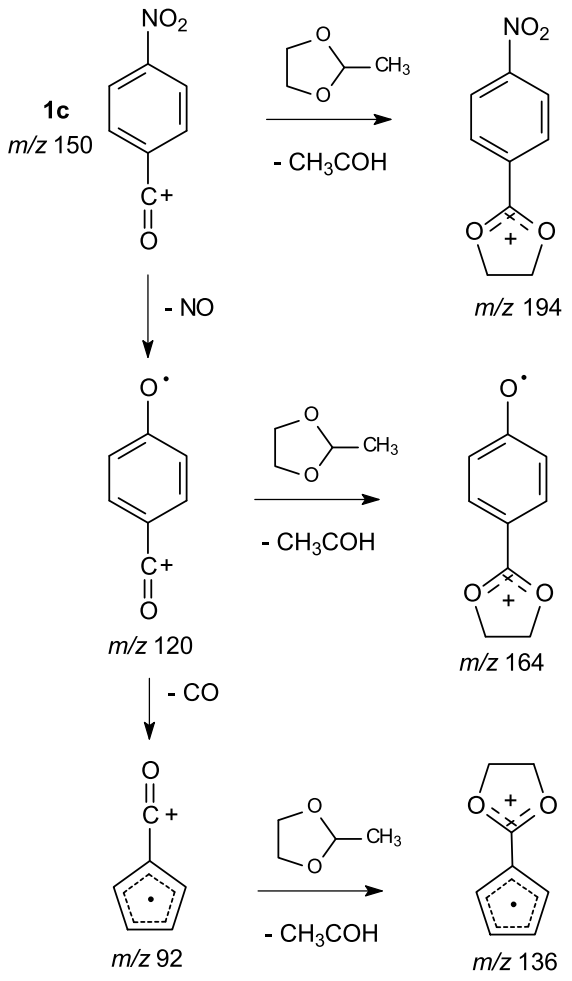

Scheme 8

important building block in organic synthesis [15], and the ortho and meta isomers are commercially unavailable.

Let us consider that the configuration (actually the whole structure) of $\mathbf{2}$ is unknown. The "unknown" molecule forms, either upon $70 \mathrm{eV}$ EI or ESI (in-source CID), a fragment ion of $\mathrm{m} / \mathrm{z} 150$, and accurate mass measurement reveals for this ion a $\mathrm{C}_{7} \mathrm{H}_{4} \mathrm{NO}_{3}$ composition that matches that of a nitrobenzoyl cation. This candidate for a configurationally diagnostic ion (the atom connectivity of such ion is still unknown) was therefore mass-selected and subjected to both CID and ion/molecule reactions with 2-methyl-1,3-dioxolane. Nearly identical spectra to those shown in Figures 2c and $3 \mathrm{c}$ were obtained, which shows that $\mathbf{1 c}$ is formed (Scheme 9). These results unequivocally prove that a fragment of the structure of the precursor molecule 2 is composed of a nitrobenzoyl group. Yet more interestingly, it is determined by MS-only data that the nitrobenzoyl group displays the para configuration!

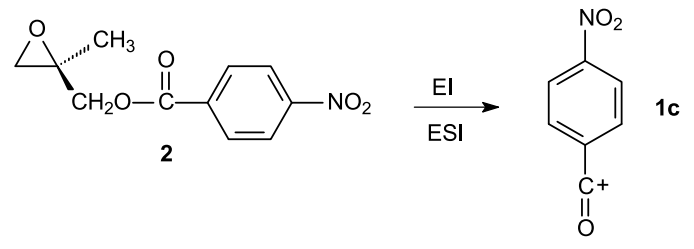

Scheme 9

\section{Conclusion}

The 2-, 3-, and 4-nitrobenzoyl cations function as conformationally diagnostic ions for the MS-only absolute ortho, meta, or para configuration assignment of acyl nitrobenzenes and their derivatives. Conformational assignment is, therefore, possible for every known or novel molecule that forms these diagnostic ions upon ionization and dissociation. As exemplified herein for 2, successful absolute configuration assignments are being continuously performed in our laboratory with an increasing number of isomeric molecules of acylbenzenes and derivatives that generate useful yields of the diagnostic nitrobenzoyl cations.

Application of this method to other classes of positional isomers depends, therefore, on finding stable and suitable configurationally diagnostic ions which may be formed by a variety of techniques such as dissociative electron ionization or electrospray, chemical, or atmospheric pressure chemical ionization followed by CID. Even ion-source CID or ionmolecule reactions [11] can be used when applying electrospray or atmospheric pressure chemical ionization. We are currently expanding this methodology to other classes of ortho/meta/para substituted aromatic compounds, and for a series of cis/trans and $\alpha / \beta$ isomers [16].

\section{Acknowledgments}

The authors thank the São Paulo State (FAPESP) and the Brazilian National Research Foundation (CNPq) for financial support.

\section{References}

1. Gozzo, F. C.; Eberlin, M. N. J. Org. Chem. 1999, 64, 2188.

2. Carvalho, M.; Gozzo, F. C.; Mendes, M. A.; Sparrapan, R.; Karcheres, C.; Eberlin, M. N. Chem. Eur. J. 1998, 4, 1161.

3. Meurer, E. C.; Eberlin, M. N. J. Mass Spectrom. 2002, 37, 146.

4. Juliano, V. F.; Gozzo, F. C.; Eberlin, M. N.; Kascheres, C.; Lago, C. L. Anal. Chem. 1996, 68, 1328.

5. Brodbel, J. S. Mass Spectrom. Rev. 1997, 16, 91. (b) Green, M. K.; Lebrilla, C. B. Mass Spectrom. Rev. 1997, 16, 53. (c) Eberlin, M. N. Mass Spectrom. Rev. 1997, 16, 113. (d) Filippi, A.; Giardini, A.; Piccirillo, S.; Speranza, M. Int. J. Mass Spectrom. 2000, 198, 137. (e) Gronert, S. Chem. Rev. 2001, 101, 329. (f) Nibbering, N. M. M. Int. J. Mass Spectrom. 2000, 200, 27. (g) Takashima, K.; Riveros, J. M. Mass Spectrom. Rev. 1998, 17, 409. (h) Eberlin, M. N. Int. J. Mass Spectrom. 2004, 235, 263.

6. McLafferty, F. W. Tandem Mass Spectrometry; Wiley: New York, 1983. (b) Levsen, K.; Schwarz, H. Mass Spectrom. Rev. 1983, 2, 77. (c) Holmes, J. L. Org. Mass Spectrom. 1985, 20, 169. (d) Busch, G.; Glish, G.; McLuckey, S. A. Mass Spectrometry/ Mass Spectrometry: Techniques and Applications of Tandem Mass Spectrometry; VCH: New York, 1988.

7. Shapiro, R. H.; Serum, J. W. Org. Mass Spectrom. 1969, 2, 333. (b) Benoit, F.; Holmes, J. L. Org. Mass Spectrom. 1970, 3, 993.

8. Eberlin, M. N.; Cooks, R. G. J. Am. Chem. Soc. 1993, 115, 9226. (b) Moraes, L. A. B.; Pimpim, R. S.; Eberlin, M. N. J. Org. Chem. 1996, 61, 8726. (c) Moraes, L. A. B.; Eberlin, M. N. J. Chem. Soc. Perkin Trans. 2 1997, 2105. (d) Sparrapan, R.; Mendes, M. A.; Eberlin, M. N. J. Mass Spectrom. 2000, 35, 189. (e) Moraes, 
L. A. B.; Eberlin, M. N. J. Am. Soc. Mass Spectrom. 2000, 11, 697. (f) Moares, L. A. B.; Eberlin, M. N. J. Am. Soc. Mass Spectrom. 2001, 12, 150. (g) Lemos, A. A.; Sparrapan, R.; Eberlin, M. N. J. Mass Spectrom. 2003, 38, 305. (h) Moraes, L. A. B.; Eberlin, M. N. J. Mass Spectrom. 2002, 37, 162.

9. Cooks, R. G.; Eberlin, M. N. Org. Mass Spectrom. 1993, 28, 679. (b) Moraes, L. A. B.; Gozzo, F. C.; Eberlin, M. N.; Vainiotalo, P. J. Org. Chem. 1997, 62, 5096. (c) Eberlin, M. N.; Cooks, R. G.; Zheng, X.; Chen, H.; Tao, W. A. Chem. Rev. submitted.

10. Eberlin, M. N.; Cooks, R. G. J. Am. Chem. Soc. 1993, 115, 9226. (b) Moraes, L. A. B.; Pimpim, R. S.; Eberlin, M. N. J. Org. Chem. 1996, 61, 8726. (c) Moraes, L. A. B.; Eberlin, M. N. J. Chem. Soc. Perkin Trans. 2 1997, 2105. (d) Sparrapan, R.; Mendes, M. A.; Eberlin, M. N. J. Mass Spectrom. 2000, 35, 189. (e) Moraes, L. A. B.; Eberlin, M. N. J. Am. Soc. Mass Spectrom. 2000, 11, 697. (f) Moares, L. A. B.; Eberlin, M. N. J. Am. Soc. Mass Spectrom. 2001, 12, 150. (g) Lemos, A. A.; Sparrapan, R.; Eberlin, M. N. J. Mass Spectrom. 2003, 38, 305. (h) Moraes, L. A. B.; Eberlin, M. N. J. Mass Spectrom. 2002, 37, 162.

11. Meurer, E. C.; Sabino, A. A.; Eberlin, M. N. Anal. Chem. 2003, 73, 4701.

12. Moraes, L. A. B.; Eberlin, M. N. J. Am. Soc. Mass Spectrom. 2001, $12,150$.

13. Moraes, L. A. B.; Eberlin, M. N. Chem. Eur. J. 2000, 6, 897.

14. Moraes, L. A. B.; Eberlin, M. N. J. Am. Chem. Soc. 1998, 120, 11136.

15. Kerdesky, F. A. J.; Schmidt, S. P.; Brooks, D. W. J. Org. Chem. 1993, 38, 3516.

16. Rocha, L. L.; Sparrapan, R.; Augusti, R.; Eberlin, M. N. J. Mass Spectrom. 2004, 39, 1176. (b) Eberlin, M. N.; Sabino, A. A., unpublished. 